\title{
Structural, and Radiation Shielding Simulation of B2O3-SiO2-LiF- ZnO-TiO2 Glasses
}

\section{Kh.S.Shaaban ( $\nabla$ khamies1078@yahoo.com )}

Al-Azhar University Faculty of Science https://orcid.org/0000-0002-5969-3089

\section{Research Article}

Keywords: Phy-X/PSD, Elastic modulus, FT-IR

Posted Date: March 15th, 2021

DOI: https://doi.org/10.21203/rs.3.rs-288612/v1

License: (c) (i) This work is licensed under a Creative Commons Attribution 4.0 International License. Read Full License 


\title{
Structural, and radiation shielding simulation of $\mathrm{B}_{2} \mathrm{O}_{3}-\mathrm{SiO}_{2}-\mathrm{LiF}-\mathrm{ZnO}-\mathrm{TiO}_{2}$ glasses
}

Kh. S. Shaaban ${ }^{1}$,

${ }^{1}$ Chemistry Department, Faculty of Science, Al-Azhar University, P.O. 71542, Assiut, Egypt

\begin{abstract}
:
Quaternary glasses with a $59 \mathrm{~B}_{2} \mathrm{O}_{3}-29 \mathrm{SiO}_{2}-2 \mathrm{LiF}-(10-x) \quad \mathrm{ZnO}-x \mathrm{TiO}_{2}$ composition using the melt-quench techniques were prepared. XRD examined the nature of prepared glasses. The FT-IR spectra was studied for the changes in the structure of these glasses. While the density is increased, the molar volume of the glass system is reduced. The velocities and elastic modulus of these glasses were experimentally and theoretically based on the MakishimaMackenzie model evaluated. Besides, for the studied glasses, the radiation shielding efficiency was investigated by Phy-X/PSD and XCOM software. These glasses were found to have an abnormal attenuation, structural, and density relationship. The mass attenuation coefficient $(\mu / \rho)$, linear attenuation coefficient (LAC), half-value layer (HVL), tenth value layer (TVL), and effective atomic number $\left(Z_{e f f}\right)$, of glasses, have been designed to simulate for gamma photon energies between 0.015 and $15 \mathrm{MeV}$. MAC values calculated using Phy-X/PSD and XCOM were compared and was observed in good agreement with the other.
\end{abstract}

Keywords: Phy-X/PSD, Elastic modulus, FT-IR.

Corresponding Author: khamies1078@yahoo.com 


\section{1-Introduction}

The specifications of materials that can serve a double function over the last century can be regarded as among the disguised targets of several researchers. Transparent glasses can be used in radiation shielding materials as a dual function. For the development of optically transparent radiation shielding materials, significant numbers of glass research labs are rising day-by-day. These materials are used in optical communication, modern optical devices, and radiation shielding materials where protection is needed from radiation [1-8].

Due to its remarkable features, such as good thermal stability, hardness, chemical stability, and so on, borosilicate glasses have become the best substitute for concrete shielding, and borosilicate glasses have improved physical characteristics like transparency and refractive index. One of the most important additives in the glass systems can be considered: $\mathrm{TiO}_{2}$, including borate, silicate, borosilicate, and phosphate glasses. The addition of $\mathrm{TiO}_{2}$ has been reported to increase the glass system's network stability and mechanical characteristics. Glasses having a higher amount of titanate confirmed the structural unit $\mathrm{TiO}_{4}, \mathrm{TiO}_{5}$, and $\mathrm{TiO}_{6}$ and their physical features depend on their number of coordinates [1-8].

To modify the characteristics of the glass, glass modifiers are incorporated into the glass network. Alkali halides [9-11] such as $\mathrm{LiF}$, and some transition metals like $\mathrm{ZnO}$, and $\mathrm{TiO}_{2}$ are included in modifiers. The melting temperature of glass and its viscosity can be affected by glass modifiers while retaining its chemical structure, as well as affecting its optical, mechanical, thermal, and shielding ability. Halides such as $\mathrm{NaF}, \mathrm{LiF}$, are introduced into the glass matrix to generate mobile ion species, $\mathrm{Li}^{+}, \mathrm{Na}^{+}$, etc. So that, halide glasses are excellent reagents for metal ions. For a long time, glasses combining halide ions were studied due to their unique physical characteristics. 
The emergence of $\mathrm{TiO}_{2}$ into the glass network improved the glass's optical, mechanical, thermal, and shielding characteristics [12-13]. Because of good conductivity of these glasses in ionic terms, it is extremely probable to use them in UV optics, solid-state batteries, and radiation protection. Depending on their concentration in the glass matrix, intermediate oxides such as $\mathrm{TiO}_{2}$ can act as either a glass modifier or former. $\mathrm{TiO}_{2}$ improves the mechanical strength and radiation protection of the host glass matrices. These glasses possess lower photon energy and a greater refractive index than other glasses. The significant development of lithium fluoride zinc titanate borosilicate glasses is very important scientifically and technologically.

It's the best study for the preparation of lithium fluoride zinc titanate borosilicate glasses and their structural, mechanical, shielding radiation, and optical properties. Thus, it is possible to find the lithium fluoride zinc titanate borosilicate glasses are suitable for use in environments exposed to radiation. The purposes of this research are to identify the attenuation proficiency of lithium fluoride zinc titanate borosilicate glasses using Phy-X/PSD [15] and XCOM software and to identify the mechanical and structure of these glasses to determine their suitability as gamma-ray shielding materials.

\section{Experimental processes and techniques.}

Glass samples in Table 1 were formulated using the melt-quench method in the chemical formula $29 \mathrm{SiO}_{2}-2 \mathrm{LiF}-59 \mathrm{~B}_{2} \mathrm{O}_{3}-(10-\mathrm{x}) \mathrm{ZnO}-x \mathrm{TiO}_{2}$, where $x:(0 \leq x \geq 10)$ mol $\%$. $\mathrm{SiO}_{2}, \mathrm{LiF}, \mathrm{H}_{3} \mathrm{BO}_{4}, \mathrm{ZnO}$, and $\mathrm{TiO}_{2}$ are the initial materials for obtaining these glasses. All the initial materials have been acquired from Sigma-Aldrich Company. Through grinding the blend repetitively to obtain a fine powder, the starting materials were blended. First, to eliminate $\mathrm{H}_{2} \mathrm{O}$ and other impurities, the base materials were heated to $650{ }^{\circ} \mathrm{C}$ for $1 \mathrm{~h}$. The heat was increased for 45 minutes to $1200{ }^{\circ} \mathrm{C}$. To reduce the internal stresses, samples were annealed at $450 \mathrm{C}$ for $2 \mathrm{~h}$ and left to cool slowly to ambient temperature. 
The glass sample's amorphous state was checked using X-ray diffraction (A Philips Xray diffractometer PW/1710). To obtain FTIR spectrums for glass samples, a Fourier transform infrared spectrometer (JASCO, FT/IR-430, Japan) was used. For this purpose, each glass powder was blended with $\mathrm{KBr}$ at a rate of 1:100 (by weight) and pressed into a pellet via a hand press. Through $4 \mathrm{~cm}^{-1}$ resolution in the $4000-400 \mathrm{~cm}^{-1}$ wavenumber range. The consequent spectra has curve-fitted to obtain quantitative values using the computer program fitting peak for the band areas of extensively overlapped bands.

The density of glass samples was estimated by Archimedes' code by using toluene as the immersion liquid. $\rho=\rho_{0}\left(\frac{M}{M-M_{1}}\right)$ where $M$ and $M_{1}$ are the weightings of glasses in the air and liquid, the glass density is $\rho$ and the density of toluene is $\rho_{0}\left(0.865 \mathrm{~g} . \mathrm{cm}^{-1}\right)$ with error $\pm 0.001 \mathrm{~g}$ $\mathrm{cm}^{-1}$. The molar volume, $V_{m}$ can be evaluated as $=\frac{M}{\rho}$ where $\mathrm{M}$ the molar weight of the glass

Using the pulse-echo technique, ultrasonic velocities, longitudinal $\left(v_{\mathrm{L}}\right)$ and shear $\left(v_{\mathrm{T}}\right)$, at ambient temperature were evaluated. In this technique, $\mathrm{x}$-cut and $\mathrm{y}$-cut transducers were used together with a digital ultrasonic flaw detector (KARL DEUTSCH Echograph model 1085) functioning at $4 \mathrm{MHz}$ with error $\pm 10 \mathrm{~m} \mathrm{~s}^{-1}$. Besides the density, the velocities were used to evaluate elastic moduli. longitudinal waves $L=\rho v_{l}^{2}$, transverse waves $G=\rho v_{t}^{2}$, Young's modulus $Y=(1+\sigma) 2 G$, bulk modulus $K=L-\left(\frac{4}{3}\right) G[15-32]$.

Elastic moduli of samples were evaluated using the exemplary based on packing density $V i=\left(\frac{3 \pi}{4}\right) N_{A}\left(m \mathrm{R}_{\mathrm{A}}^{3}+n \mathrm{R}_{\mathrm{O}}^{3}\right) m^{3} \cdot m o l^{-1}$, and dissociation energy $G i=\left(\frac{1}{V_{m}}\right) \sum_{i} G i X i$, the metallic and oxygen Pauling ionic radii are $R_{m}$ and $R_{O}$. Longitudinal waves $\quad L=$ $K+\left(\frac{4}{3}\right) G, \quad$ transverse waves $G=30 *\left(\frac{V_{i}^{2} G_{i}}{V_{i}}\right) \quad$ Young's modulus $Y=8.36 V_{i} G_{i}$, bulk modulus $K=10 V_{i}^{2} G_{i}$. Poisson's ratio $\sigma=\frac{1}{2}-\left(\frac{1}{7.2^{*} V i}\right)$. Acoustic Impedance; $Z=v_{L} \rho$. 
Micro Hardness; $\quad \mathrm{H}=\frac{(1-2 \sigma) \mathrm{Y}}{6(1+\sigma)}$. Debye Temperature: $\theta_{D}=\frac{h}{k}\left(\frac{9 N_{A}}{4 \pi V_{m}}\right)^{\frac{1}{3}} M_{S}, \quad$ Where $h$ and $k$ are the constants of Planck and Boltzmann and $N_{A}$ is the number of Avogadro [33-34].

Average velocities, $M_{S}=\frac{1}{3}\left(\frac{\frac{2}{v_{T}^{3}}}{\frac{1}{v_{l}^{3}}}\right)^{\frac{1}{3}} . \quad$ Thermal coefficient of expansion, $\alpha_{P=23.2\left(v_{L}-0.57457\right)}$. Volume of the oxygen molar, $V_{o}=\left(\frac{M}{\rho}\right)\left(\frac{1}{\Sigma x i n i}\right)$, Density of Packing, $O P D=\left(\frac{1000 C}{V m}\right)\left(\frac{M o l}{L}\right)$.

In this article, radiation parameters have been computed using Phy-X/PSD software and these parameters are calculated using the following equations: the coefficient of mass attenuation samples $(\mu / \rho)=\sum_{i} x_{i}(\mu / \rho)_{i}$. Effective atomic number $Z_{e f f}=\frac{\sum_{i} f_{i} A_{i}(\mu / \rho)_{i}}{\sum_{j} f_{j} \frac{A_{j}}{Z_{j}}(\mu / \rho)_{j}}$. Half and tenth value layer (HVL), and (TVL): $H V L=\frac{0.693}{L A C}, T V L=\frac{2.3}{L A C}$

\section{Results and Discussions}

\subsection{XRD studies}

No discrete lines, no sharp peaks, were confirmed by XRD patterns as exemplified in Fig. 1 and indicate that the samples have a high amorphous state. The width of the halo varies from one sample to another, but no indication of crystalline phase has been shown in all the samples.

\subsection{Investigations of FT-IR}

FT-IR spectra are exemplified in Fig. 2 for titanium borosilicate glasses. To obtain accurate band positions in the FT-IR spectrum, Deconvoluted process is used. Residue results were plotted to get the quality in the FT-IR deconvolution fitting, and the variation is less than $0.02 \%$ in the experimental and simulated graphs. Gaussian fit of FT-IR spectrum of these glasses is exemplified in Fig. 3 and Table 2, respectively. The structural units of the network in 
these glasses were identified and summarized as: The band at $\sim 444-490 \mathrm{~cm}^{-1}$ is related to the network structure's deformation modes. Bands in the $562-570 \mathrm{~cm}^{-1}$ region had been ascribed to $\left(\mathrm{LiO}_{6}\right),\left(\mathrm{ZnO}_{6}\right)$, and $\left(\mathrm{TiO}_{4}\right)$ vibrations and they overlap with the O-Si-O unit bending vibrations. The band at $\sim 680-691 \mathrm{~cm}^{-1}$ is assigned to the bending vibrations of the bridging oxygen atom. The band at $\sim 890 \mathrm{~cm}^{-1}$ is assigned to the tri-, tetra-, and penta-borate groups' stretching vibrations. The band at $\sim 1120-1044 \mathrm{~cm}^{-1}$ is assigned to $\mathrm{B}-\mathrm{O}$ stretching $\mathrm{BO}_{4}$ tetrahedra vibrations. The band at $\sim 1120-890 \mathrm{~cm}^{-1}$ is assigned to $\mathrm{B}-\mathrm{O}$, bridge in the $\mathrm{BO}_{4}$, and a major component of asymmetric stretching of $\mathrm{BO}_{4}$ tetrahedron. The band at $\sim 1240-1260 \mathrm{~cm}^{-1}$ is assigned to trigonal $\mathrm{BO}_{3}$ units of $\mathrm{B}-\mathrm{O}$ bond stretching. The observed band at $\sim 1360-1350 \mathrm{~cm}^{-1}$ is assigned to B-O stretching vibrations that mainly involve divers' groups of connected oxygen. B-O symmetric stretching vibrations of different borate groups are due to the band at $\sim 1650-1500 \mathrm{~cm}^{-1}$. FT-IR spectral causes a shift to higher wavenumbers with an increase in titanium concentration. Also, the structure becomes more compact by incorporating $\mathrm{TiO}_{2}$, as $\mathrm{TiO}_{4}$ species are produced. Boron transforms from $\mathrm{BO}_{3}$ into $\mathrm{BO}_{4}$ tetrahedra after alkali metal halide is incorporated [25-32]. This increases the coherence of the glass network and the structure stiffening.

\subsection{Investigations of Mechanical}

Glass density raised as $\mathrm{TiO}_{2}$ content increased and molar volume reduced as Fig. 4. The density increase is ascribed to the transformation of the $\mathrm{BO}_{3}$ triangles into the tetrahedral $\mathrm{BO}_{4}$ of the glass network with the progressive replacement of $\mathrm{ZnO}$ with $\mathrm{TiO}_{2}$. Rising density results affect the stiffness of the glass network and the increase in rigidity. Enhanced density values also reflect an increase in the density of cross-links. The density increase may also be due to the rise in oxygen in the glass network. The mixed oxide effect may be contributed to a variation in density and molar volume. These results are like the FT-IR results. 
The velocity of prepared glasses with different amounts of $\mathrm{TiO}_{2}$ was illustrated in Fig. 4. Both velocities $\left(v_{L}\right.$ and $\left.v_{T}\right)$ were increased, as shown in Table 3 , by an increase in $\mathrm{TiO}_{2}$, and $\left(v_{L}\right)$ values higher than $\left(v_{T}\right)$. This increase in the estimated ultrasonic velocity is possible to explain by considering variables:

(i) Increasing $\mathrm{TiO}_{2}$ will enhance the amorphous network by increasing the concentration of $\mathrm{TiO}_{4}$ and $\mathrm{TiO}_{6}$ structural units with higher coordination in comparison with $\mathrm{ZnO}$ structural unit.

(ii) Consequently, there was an increased polymerization of the glass coordination number, cross-link density, and connectivity within the glass network.

(iii) Because of the increase in internal energy, the velocities were increased.

Experimentally and theoretically, elastic modules were evaluated for prepared glasses and exemplified in Figs $6 \& 7$. The elastic moduli exactly as noticed of velocities as exemplified in Fig. 6 \& 7 i.e., it depends on the nature of bonds in the glass and the cross-link density. With the increase of $\mathrm{TiO}_{2}$, the elastic moduli value shows an increasing trend. The rise in elastic modules as the number of coordinates raised, and bond strength of $\mathrm{Ti}-$ $\mathrm{O}(73 \mathrm{KCal} / \mathrm{mol})$ is higher than $\mathrm{Zn}-\mathrm{O}(36 \mathrm{KCal} / \mathrm{mol})$. As the modification role of $\mathrm{TiO}_{2}$ in the glass system, all mechanical parameters as revealed in Table 4 are increased with the increase in $\mathrm{TiO}_{2}$ content.

\subsection{Photon Shielding Features}

Concerning mass attenuation coefficient values (MAC) obtained by Phy-X/PSD software with a photon energy range of $0.015-15 \mathrm{MeV}$. Because MAC is characterized by the material absorbed to attenuate radiation, a higher value indicates a more impenetrable shield. Phy-X/PSD and X-com performance, MAC values concerning the energy and $\mathrm{TiO}_{2}$ mol $\%$ were exemplified in Figs. $8 \& 9$. More clearly, it is from Figs. $8 \& 9$ that the impact of the glass structure plays an important role in improving the MAC values of these glasses. The 
highest values of MAC are found at low energy, and with the shift towards greater energy, MAC decreased rapidly. The MAC of the glasses reduces as energy increases as more photons can absorb through the sample, reducing its absorbency, and reducing MAC. This sequence also shows that samples are the most efficient at lower energies. Their shielding capacity becomes less efficient when energy increases. Besides, Ti has a lower atomic number (22) than $\mathrm{Zn}$ (33). The atomic number correlates positively with MAC, causing the highest radiation shielding capability in the glass sample G 1 . Even so, the G1 glass can be the most superior attenuation abilities to the other glasses [35-42].

As shown in Table 5, MAC values calculated using Phy-X/PSD and XCOM are compared. The other is in excellent agreement with these values. The Phy-X/PSD and XCOM deviations were calculated as Deviation $\%=\left[\frac{(\mu / \rho)_{P h y-X}-(\mu / \rho)_{X C O M}}{(\mu / \rho)_{P h y-X}}\right] x 100$, The dev. $\%$ acquired is small, which provides the Phy-X results [43].

LAC is a useful method for calculating the glasses' attenuation shielding efficiency, which also demonstrates the same trend as MAC. Figs.10 exemplified LAC with the photon energy. The atomic number plays a critical role in improving LAC values. In general, with the decrease in atomic number LAC and MAC are decreased. The identified LAC values follow the G1 $>$ G2 $>$ G3 $>$ G4 $>$ G5 $>$ G6 trend for all energies. These data indicated that the LAC values are associated with the atomic number of titanates, causing G1 to be the highest LAC. It is possible to describe the reduction using the same reasoning as for MAC.

Figure 11 exemplified $H V L$ as a photon energy function. It was observed that $H V L$ values an increasing with energy. So, G1 the most attractive shield than the other samples examined. This result suggests that, at a lower energy level, glasses are much more effective, while reducing efficiency as excess energy. Figure 12 exemplified $T V L$ as a 
photon energy function. The TVL values increased with the increase in photon energy in all the examined glasses. TVL was analogous with HVL values.

Figure 13 exemplified $Z_{\text {eff }}$ as a photon energy function. $Z_{\text {eff }}$ symbolizes the mean atomic number, with a higher value suggesting a good shield. G1 has been reported the highest value. This behavior can be explained as Ti has a lower atomic number (22) than $\mathrm{Zn}$ (33). This behavior indicates that it is further needed to increase the titanate in the glasses. The $Z_{\text {eff }}$ values decreased with the increase in photon energy in all the examined glasses. The photoelectric effect is strongly dependent on the atomic number, therefore the glasses containing $\mathrm{Zn}$ have a quickly reducing $Z_{\text {eff }}$ since $\mathrm{Zn}$ has an atomic number of 30 . The G6 glass sample shows the smallest potential for shielding than other samples.

\section{Conclusions}

In the current study the glass containing different amounts of titanate with the formula $59 \mathrm{SiO}_{2}-29 \mathrm{SiO}_{2}-2 \mathrm{LiF}-(10-\mathrm{x}) \mathrm{ZnO}-\mathrm{xTiO}_{2}$ where $x=(0 \leq x \geq 10)$ conventional meltquenching methods have been manufactured. The structure, mechanical, and shielding variables have been examined for these glasses. The findings showed the following objects:

1- XRD measurements established the amorphous nature of glasses.

2- As $\mathrm{TiO}_{2}$ content rises, the density of the samples raised while the molar volume reduced.

3- Ultrasonic velocities of these glasses were increased with increasing $\mathrm{TiO}_{2}$ concentration.

4- Gamma shielding characteristics of these glasses were predictable by the Phy-X / PSD and XCOM program between $0.015-15 \mathrm{MeV}$. The effect of the addition of $\mathrm{TiO}_{2}$ on the shielding ability of the glasses was discussed and we found that: (i) The mass attenuation coefficient decreased with the increase of the concentration of $\mathrm{TiO}_{2}$ from 0 mol. $\%$ to 10 mol. $\%$, (ii) The sample coded as $\mathrm{G} 1$ possesses the lowest 
HVL while highest $Z_{\text {eff. }}$ (iii) Lithium fluoride zinc titanate borosilicate glasses were found to have an abnormal attenuation, structural, and density relationship.

The results obtained have shown that the increase in $\mathrm{TiO}_{2}$ concentration in the glass system can lead to a significant improvement in the attenuation, structural, and mechanical properties. Furthermore, it is possible to use this glass in aircraft bodies, a shield from radiation in the $\mathrm{x}$ ray centers, facades of houses.

Author contributions: Kh. S. Shaaban: performing XRD, UV measurements and analysis, Writing-review, writing the manuscript, Methodology, Software, and writing - discussion.

\section{Acknowledgments:}

Availability of data and material: My manuscript and associated personal data will be shared with Research Square for the delivery of the author dashboard.

Compliance with ethical standards: The manuscript has not been published elsewhere and has not been submitted simultaneously for publication elsewhere.

Conflict of interest: The authors declare that they have no conflict of interest.

Declaration of Competing Interest: The authors declare that they have no known competing financial interests or personal relationships that could have appeared to influence the work reported in this paper.

Funding statement: There are currently no Funding Sources on the list

Consent to participate: The authors consent to participate.

Consent for Publication: The author consent for publication. 


\section{References}

[1] El-Damrawi, G., Abdelghany, A.M., Hassan, A.K. et al. (2020) Effect of $\mathrm{BO}_{4}$ and $\mathrm{FeO}_{4}$ Structural Units on Conduction Mechanism of Iron Borosilicate Glasses. Silicon. https://doi.org/10.1007/s12633-020-00694-w

[2] Shaaban, K.S., Wahab, E.A.A., Shaaban, E.R. et al. (2020). Electronic Polarizability, Optical Basicity, Thermal, Mechanical and Optical Investigations of $\left(65 \mathrm{~B}_{2} \mathrm{O}_{3}-30 \mathrm{Li}_{2} \mathrm{O}-5 \mathrm{Al}_{2} \mathrm{O}_{3}\right)$ Glasses Doped with Titanate. Journal of Elec Materi 49, 2040-2049. https://doi.org/10.1007/s11664-019-07889-x

[3] Wahab, E. A. A., \& Shaaban, K. S. (2018). Effects of $\mathrm{SnO}_{2}$ on spectroscopic properties of borosilicate glasses before and after plasma treatment and its mechanical properties. Materials Research Express, 5(2), 025207, doi:10.1088/2053-1591/aaaee8

[4] Shaaban, K.S., Abo-Naf, S.M. \& Hassouna, M.E.M. (2019). Physical and Structural Properties of Lithium Borate Glasses Containing $\mathrm{MoO}_{3}$. Silicon 11, 2421-2428 https://doi.org/10.1007/s12633-016-9519-4

[5] Abdel Wahab, E.A., Shaaban, K.S., Elsaman, R. et al. (2019). Radiation shielding, and physical properties of lead borate glass doped $\mathrm{ZrO}_{2}$ nanoparticles. Appl. Phys. A 125, 869 https://doi.org/10.1007/s00339-019-3166-8

[6] Abd-Allah, W.M., Saudi, H.A., Shaaban, K.S. et al. (2019), Investigation of structural and radiation shielding properties of $40 \mathrm{~B}_{2} \mathrm{O}_{3}-30 \mathrm{PbO}-(30-x) \mathrm{BaO}-x \mathrm{ZnO}$ glass system. Appl. Phys. A 125, 275 https://doi.org/10.1007/s00339-019-2574-0

[7] Shaaban, K. S., Abo-naf S. M., Abd Elnaeim, A. M., \& Hassouna, M. E. M. (2017). Studying effect of $\mathrm{MoO}_{3}$ on elastic and crystallization behavior of lithium diborate glasses. Appl. Phys. A, 123(6), doi:10.1007/s00339-017-1052-9

[8] Shaaban, K.S., Yousef, E.S., Abdel Wahab, E.A. et al. (2020). Investigation of Crystallization and Mechanical Characteristics of Glass and Glass-Ceramic with the 
Compositions $x \mathrm{Fe}_{2} \mathrm{O}_{3}-35 \mathrm{SiO}_{2}-35 \mathrm{~B}_{2} \mathrm{O}_{3}-10 \mathrm{Al}_{2} \mathrm{O}_{3}-(20-x) \quad \mathrm{Na}_{2} \mathrm{O}$. J. of Materi $\quad \mathrm{Eng}$ and Perform. https://doi.org/10.1007/s11665-020-04969-6

[9] Okasha A, Marzouk SY, Hammad AH, Abdelghany AM (2017). Optical character inquest of cobalt containing fluoroborate glass. Optik - Int J Light Electron Opt 142:125-133 https://doi.org/10.1016/j.ijleo.2017.05.088

[10] Shakespeare, W. (2002). Halide Glass. Structural Chemistry of Glasses, 1-12. doi:10.1016/b978-008043958-7/50019-4

[11] Yamane, M., Kawazoe, H., Inoue, S., \& Maeda, K. (1985). IR transparency of the glass of $\mathrm{ZnCl}_{2}-\mathrm{KBr}-\mathrm{PbBr}_{2}$ system. Materials Research Bulletin, 20(8), 905-911. doi:10.1016/00255408(85)90073-X

[12] Shaaban, K.S., Koubisy, M.S.I., Zahran, H.Y. et al. (2020). Spectroscopic Properties, Electronic Polarizability, and Optical Basicity of Titanium-Cadmium Tellurite Glasses Doped with Different Amounts of Lanthanum. J Inorg Organomet Polym. https://doi.org/10.1007/s10904-020-01640-4

[13] Shaaban, K.S., Yousef, E.S., Mahmoud, S.A. et al. (2020). Mechanical, Structural and Crystallization Properties in Titanate Doped Phosphate Glasses. J Inorg Organomet. Polym https://doi.org/10.1007/s10904-020-01574-X

[14] Somaily, H.H., Shaaban, K.S., Makhlouf, S.A. et al. Comparative Studies on Polarizability, Optical Basicity and Optical Properties of Lead Borosilicate Modified with Titania. J Inorg Organomet Polym (2020). https://doi.org/10.1007/s10904-020-01650-2

[15] Şakar, E., Özpolat, Öü.F1., Alım, Bü., Sayyed, M.I., Kurudirek, M., (2020). PhyX / PSD: Development of a user friendly online software for calculation of parameters relevant to radiation shielding and dosimetry, Radiation Physics and Chemistry 166, 108496, https://doi.org/10.1016/j.radphyschem.2019.108496 
[16] Shaaban, K.S., Zahran, H.Y., Yahia, I.S. et al. (2020), Mechanical and radiation-shielding properties of $\mathrm{B}_{2} \mathrm{O}_{3}-\mathrm{P}_{2} \mathrm{O}_{5}-\mathrm{Li}_{2} \mathrm{O}-\mathrm{MoO}_{3}$ glasses. Appl. Phys. A 126, (10), 804. https://doi.org/10.1007/s00339-020-03982-9

[17] Saudi, H.A., Abd-Allah, W.M. \& Shaaban, K.S. (2020). Investigation of gamma and neutron shielding parameters for borosilicate glasses doped europium oxide for the immobilization of radioactive waste. J Mater Sci: Mater Electron 31(9), 6963-6976, https://doi.org/10.1007/s10854-020-03261-6

[18] El-Sharkawy, R. M., Shaaban, K. S., Elsaman, R., Allam, E. A., El-Taher, A., \& Mahmoud, M. E. (2020). Investigation of mechanical and radiation shielding characteristics of novel glass systems with the composition $\mathrm{xNiO}-20 \mathrm{ZnO}-60 \mathrm{~B}_{2} \mathrm{O}_{3}-(20-\mathrm{x}) \mathrm{CdO}$ based on nano metal oxides. Journal of Non-Crystalline Solids, 528,119754 doi: 10.1016/j.jnoncrysol.2019.119754

[19] El-Rehim, A.F.A., Shaaban, K.S., Zahran, H.Y. et al. (2020). Structural and Mechanical Properties of Lithium Bismuth Borate Glasses Containing Molybdenum (LBBM) Together with their Glass-Ceramics. J Inorg Organomet Polym https://doi.org/10.1007/s10904-020-01708-1 [20] El-Maaref, A. A., Wahab, E. A. A., Shaaban, K. S., Abdelawwad, M., Koubisy, M. S. I., Börcsök, J., \& Yousef, E. S. (2020). Visible and mid-infrared spectral emissions and radiative rates calculations of $\mathrm{Tm}^{3+}$ doped BBLC glass. Spectrochimica Acta Part A: Molecular and Biomolecular Spectroscopy, 118774. doi: 10.1016/j.saa.2020.118774

[21] Gedam, R.S., Ramteke, D.D. (2012). Synthesis and Characterization of Lithium Borate Glasses Containing $\mathrm{La}_{2} \mathrm{O}_{3}$. Trans Indian Inst Met 65, 31-35. https://doi.org/10.1007/s12666$\underline{011-0107-4}$ 
[22] Fayad, A.M., Abd-Allah, W.M. \& Moustafa, F.A. (2018). Effect of Gamma Irradiation on Structural and Optical Investigations of Borosilicate Glass Doped Yttrium Oxide. Silicon 10, 799-809.https://doi.org/10.1007/s12633-016-9533-6

[23] Kaewjaeng, S., Kothan, S., Chaiphaksa, W., Chanthima, N., Raja Ramakrishna, R., Kim, H. J., \& Kaewkhao, J. (2019), High transparency $\mathrm{La}_{2} \mathrm{O}_{3}-\mathrm{CaO}-\mathrm{B}_{2} \mathrm{O}_{3}-\mathrm{SiO}_{2}$ glass for diagnosis xrays shielding material application, Radiation Physics and Chemistry, 160,4147, 10.1016/j.radphyschem.2019.03.018

[24] Shaaban, K., Abdel Wahab, E.A., El-Maaref, A.A. et al. (2020). Judd-Ofelt analysis and physical properties of erbium modified cadmium lithium gadolinium silicate glasses. J Mater Sci: Mater Electron 31, 4986-4996 https://doi.org/10.1007/s10854-020-03065-8

[25] El-Maaref, A. A., Shimaa Badr, Shaaban, K. S., Wahab, E. A. A., \& ElOkr, M. M. (2019), Optical Properties and Radiative Rates of $\mathrm{Nd}^{3+}$ Doped Zinc-Sodium Phosphate Glasses. Journal of Rare Earths 37, 3, 253-259 doi: 10.1016/j.jre.2018.06.006

[26] Shaaban, K.S., Wahab, E.A.A., Shaaban, E.R. et al. (2020). Electronic polarizability, optical basicity and mechanical properties of aluminum lead phosphate glasses. Opt Quant Electron 52, 125 https://doi.org/10.1007/s11082-020-2191-3

[27] Shaaban, K. S., El Sayed Yousef. (2020), Optical properties of $\mathrm{Bi}_{2} \mathrm{O}_{3}$ doped boro tellurite glasses and glass ceramics. Optik - International Journal for Light and Electron Optics 203, 163976. https://doi.org/10.1016/j.ijleo.2019.163976

[28] El-Rehim, A.A., Zahran, H., Yahia, I. et al. (2020). Radiation, Crystallization, and Physical Properties of Cadmium Borate Glasses. Silicon https://doi.org/10.1007/s12633-02000798-3

[29] E.A. Abdel Wahab, A.A. El-Maaref, Kh.S. Shaaban, J. Börcsök, M. Abdelawwad, 
(2020), Lithium cadmium phosphate glasses doped $\mathrm{Sm}^{3+}$ as a host material for near-IR laser applications, Optical Materials,110638, https://doi.org/10.1016/j.optmat.2020.110638.

[30] E.A. Abdel Wahab, M.S.I. Koubisy, M.I. Sayyed, K.A. Mahmoud, A.F. Zatsepin, Sayed A. Makhlouf, Shaaban, Kh.S. (2020), Novel borosilicate glass system: $\mathrm{Na}_{2} \mathrm{~B}_{4} \mathrm{O}_{7}-\mathrm{SiO} 2-\mathrm{MnO}_{2}$ Synthesis, average electronics polarizability, optical basicity, and gamma-ray shielding features, Journal of Non-Crystalline Solids, https://doi.org/10.1016/j.jnoncrysol.2020.120509

[31] El-Rehim, A.F.A., Zahran, H.Y., Yahia, I.S. et al. (2020). Physical, Radiation Shielding and Crystallization Properties of $\mathrm{Na}_{2} \mathrm{O}-\mathrm{Bi}_{2} \mathrm{O}_{3^{-}} \quad \mathrm{MoO}_{3}-\mathrm{B}_{2} \mathrm{O}_{3^{-}} \quad \mathrm{SiO}_{2^{-}}$ $\mathrm{Fe}_{2} \mathrm{O}_{3}$ Glasses. Silicon https://doi.org/10.1007/s12633-020-00827-1

[32] Abdel Wahab, E.A., Shaaban, K.S. \& Yousef, E.S. (2020), Enhancement of optical and mechanical properties of sodium silicate glasses using zirconia. Opt Quant Electron 52, 458. https://doi.org/10.1007/s11082-020-02575-3

[33] Makishima, A. and J.D. Mackenzie, Direct calculation of Young's modulus of glass. Journal of Non-Crystalline Solids, 12(1), 35-45. (1973). https://doi.org/10.1016/0022$\underline{3093(73) 90053-7}$

[34] Makishima, A. and J.D. Mackenzie, Calculation of bulk modulus, shear modulus, and Poisson's ratio of glass. Journal of Non-crystalline solids, 17(2) 147-157. (1975). https://doi.org/10.1016/0022-3093(75)90047-2

[35] Savidh Khan, G. Kaur, K. Singh, (2017), Effect of $\mathrm{ZrO}_{2}$ on dielectric, optical and structural properties of yttrium calcium borosilicate glasses, Ceramics International, 43, (1) 722-727. https://doi.org/10.1016/j.ceramint.2016.09.219.

[36] AlBuriahi, M. S., H. H. Hegazy, Faisal Alresheedi, I. O. Olarinoye, H. Algarni, H. O. Tekin, and H. A. Saudi (2020) Effect of $\mathrm{CdO}$ addition on photon, electron, and neutron attenuation properties of boro-tellurite glasses. Ceramics International doi.org/10.1016/j.ceramint.2020.10.168 
[37] Stalin, Salavadi, D. K. Gaikwad, M. S. Al-Buriahi, Ch Srinivasu, Shaik Amer Ahmed, H. O. Tekin, and Syed Rahman. (2020) Influence of $\mathrm{Bi}_{2} \mathrm{O}_{3} / \mathrm{WO}_{3}$ substitution on the optical, mechanical, chemical durability and gamma ray shielding properties of lithium-borate glasses. Ceramics International https://doi.org/10.1016/j.ceramint.2020.10.109

[38] Al-Buriahi, M.S., Somaily, H.H., Alalawi, A. et al. (2020). Polarizability, Optical Basicity, and Photon Attenuation Properties of $\mathrm{Ag}_{2} \mathrm{O}-\mathrm{MoO}_{3}-\mathrm{V}_{2} \mathrm{O}_{5}-\mathrm{TeO}_{2}$ Glasses: The Role of Silver Oxide. J Inorg Organomet Polym https://doi.org/10.1007/s10904-020-01750-Z

[39] Al-Buriahi, M. S., Y. S. M. Alajerami, A. S. Abouhaswa, Amani Alalawi, Tanin Nutaro, and Baris Tonguc. (2020): Effect of chromium oxide on the physical, optical, and radiation shielding properties of lead sodium borate glasses. Journal of Non-Crystalline Solids 544 120171. https://doi.org/10.1016/j.jnoncrysol.2020.120171

[40] Abouhaswa, A. S., M. H. A. Mhareb, Amani Alalawi, and M. S. Al-Buriahi. (2020) Physical, structural, optical, and radiation shielding properties of $\mathrm{B}_{2} \mathrm{O}_{3}-20 \mathrm{Bi}_{2} \mathrm{O}_{3}-20 \mathrm{Na}_{2} \mathrm{O}_{2}-$ $\mathrm{Sb}_{2} \mathrm{O}_{3}$ glasses: Role of $\mathrm{Sb}_{2} \mathrm{O}_{3}$. Journal of Non-Crystalline Solids 543: 120130. https://doi.org/10.1016/j.jnoncrysol.2020.120130

[41] Naseer, K. A., K. Marimuthu, M. S. Al-Buriahi, Amani Alalawi, and H. O. Tekin. (2020), Influence of $\mathrm{Bi}_{2} \mathrm{O}_{3}$ concentration on barium-telluro-borate glasses: physical, structural, and radiation-shielding properties. Ceramics International 47, 1: 329-340.

https://doi.org/10.1016/j.ceramint.2020.08.138

[42] Abouhaswa, A.S., Al-Buriahi, M.S., Chalermpon, M. et al. (2020), Influence of $\mathrm{ZrO}_{2}$ on gamma shielding properties of lead borate glasses. Appl. Phys. A 126, 78 . https://doi.org/10.1007/s00339-019-3264-7

[43] Gokhan Kilic, F.I.El Agawany, Buse Ozen Ilik, K.A. Mahmoud, Erkan Ilik, Y.S. Rammah, (2021), $\mathrm{Ta}_{2} \mathrm{O}_{5}$ reinforced $\mathrm{Bi}_{2} \mathrm{O}_{3}-\mathrm{TeO}_{2}-\mathrm{ZnO}$ glasses: Fabrication, physical, structural 
characterization, and radiation shielding efficacy, Optical Materials, 112, 110757, ttps://doi.org/10.1016/j.optmat.2020.110757. 
Figures

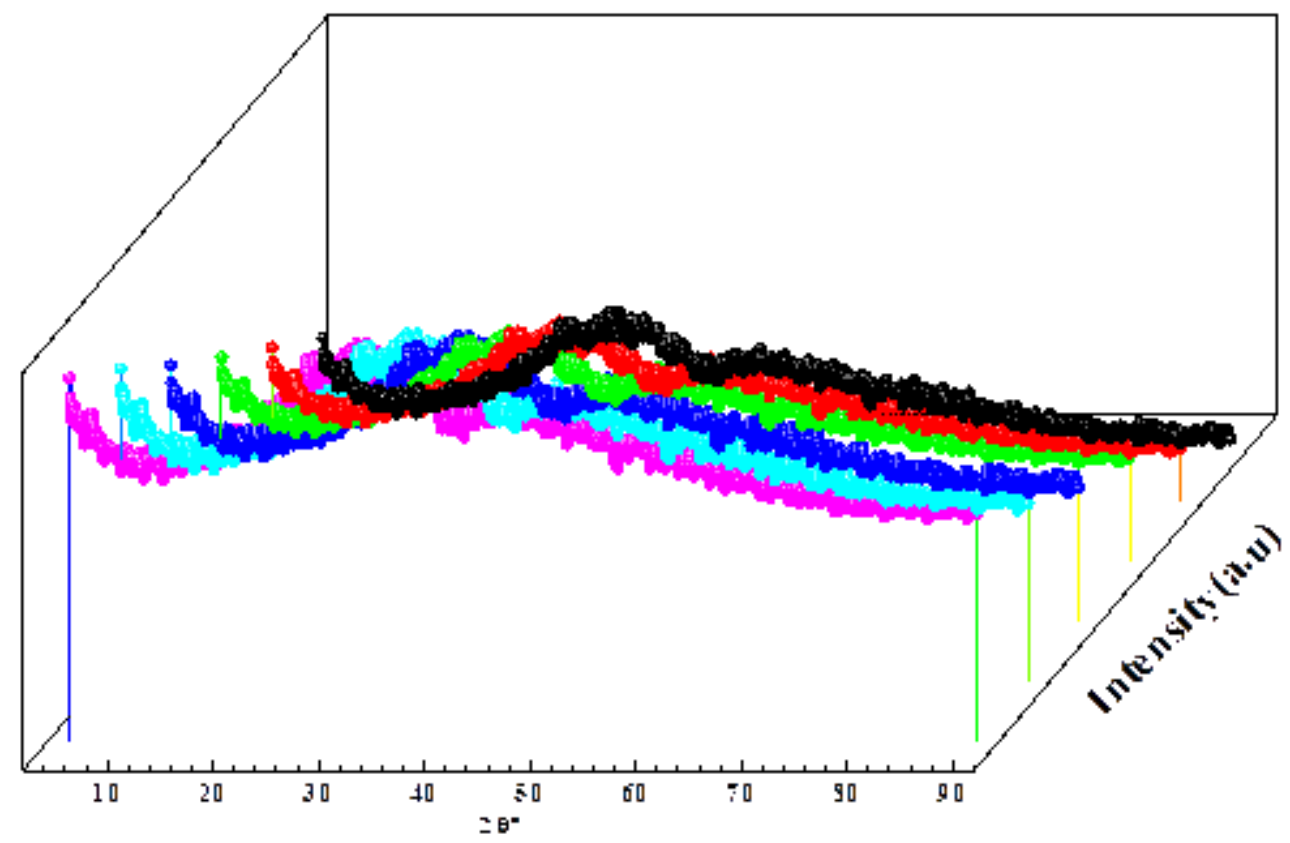

Figure 1

XRD of the studied glasses. 


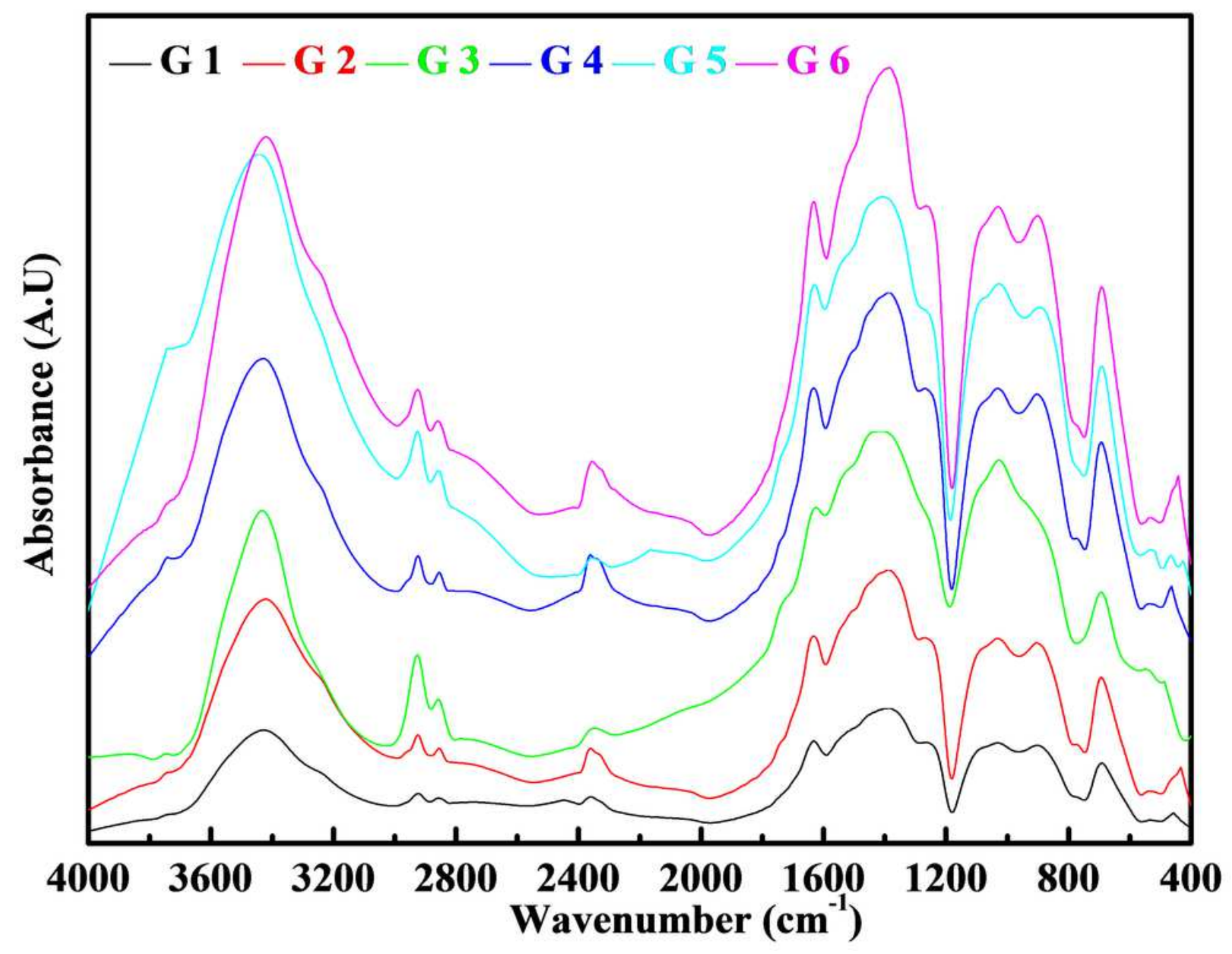

Figure 2

FT-IR spectra of prepared glasses. 

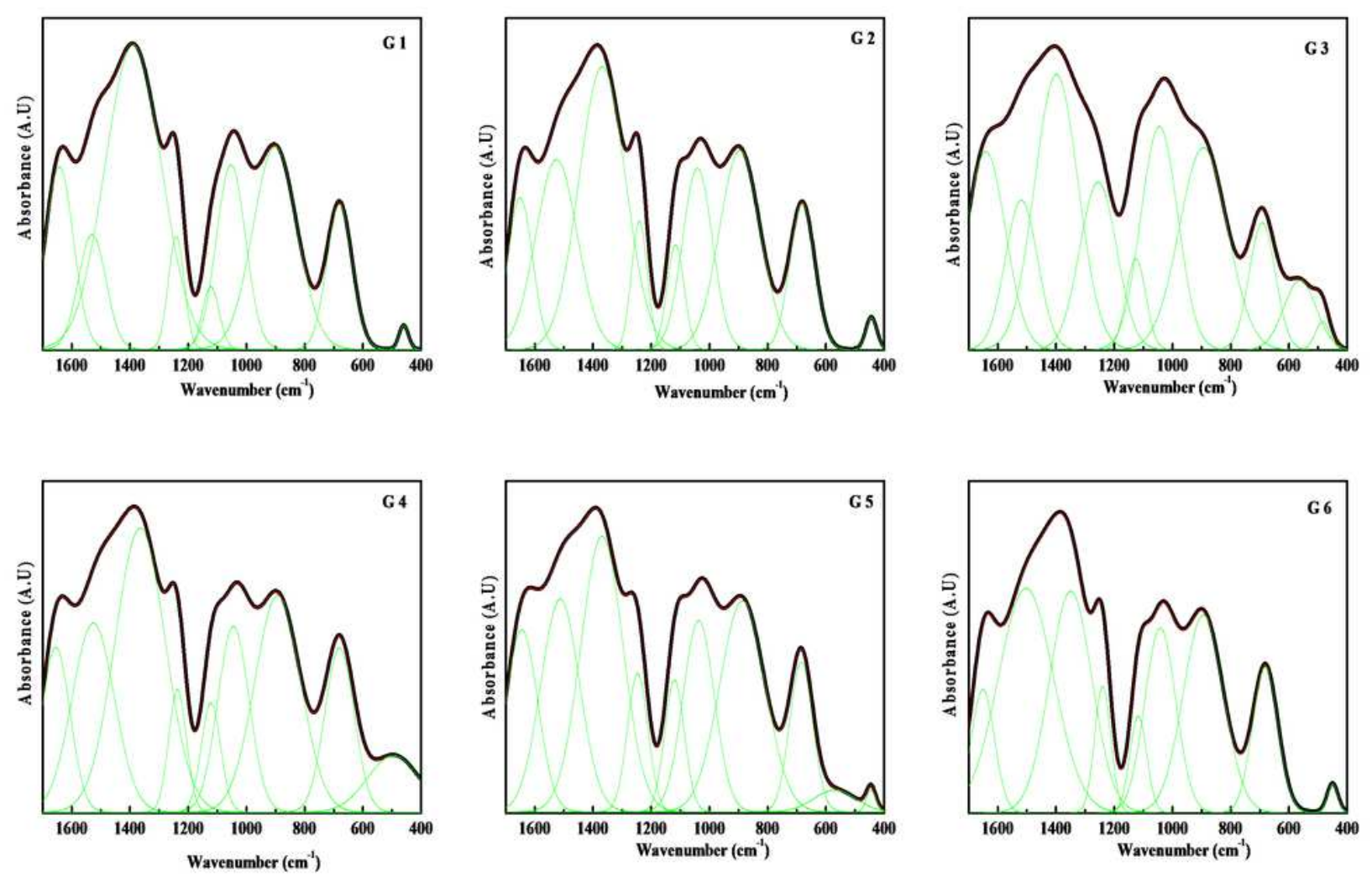

Figure 3

The Gaussian fit of the FT-IR spectrum of prepared glasses. 


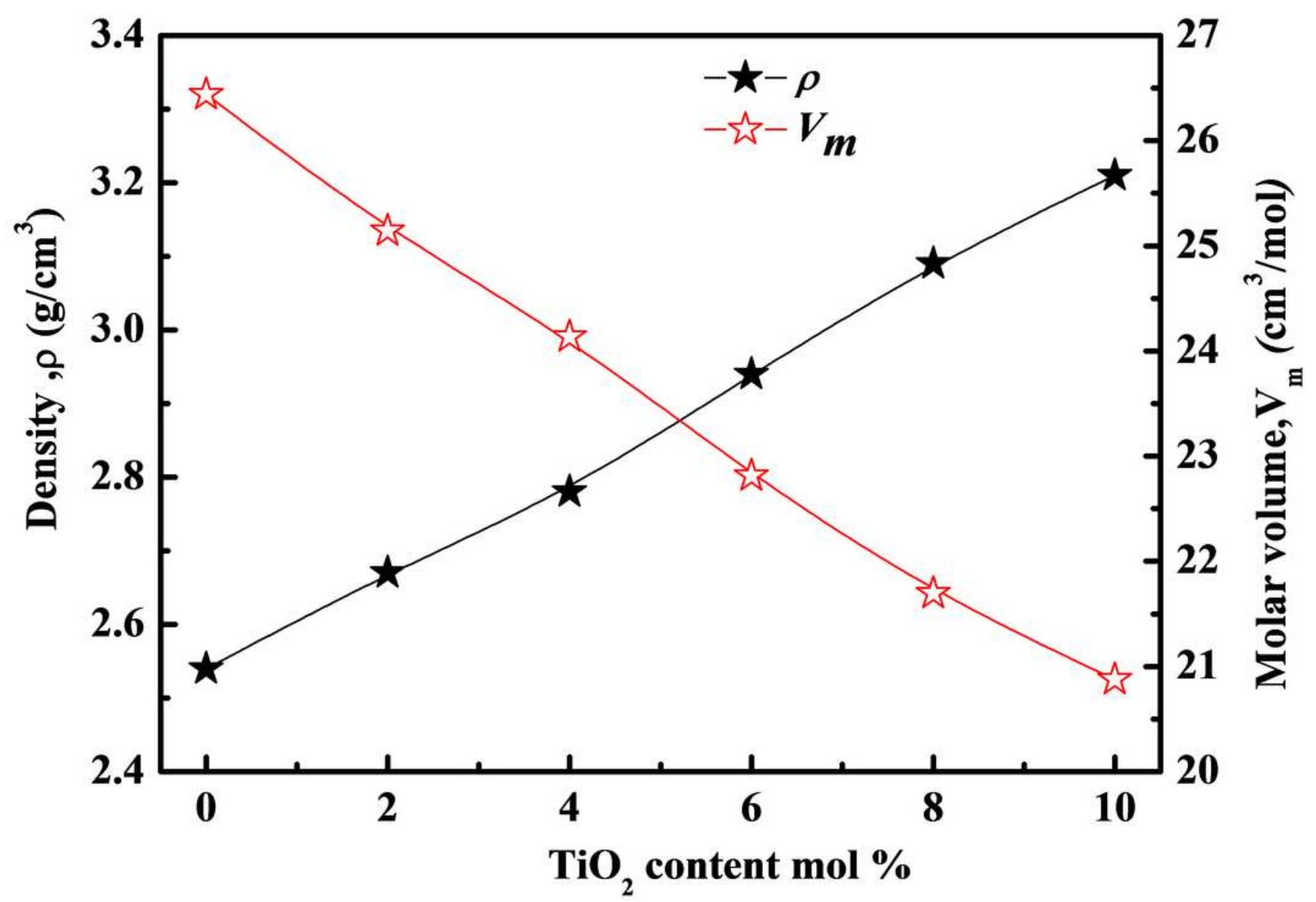

Figure 4

Glass density and molar volume as a function of $\mathrm{TiO} 2$ content. 


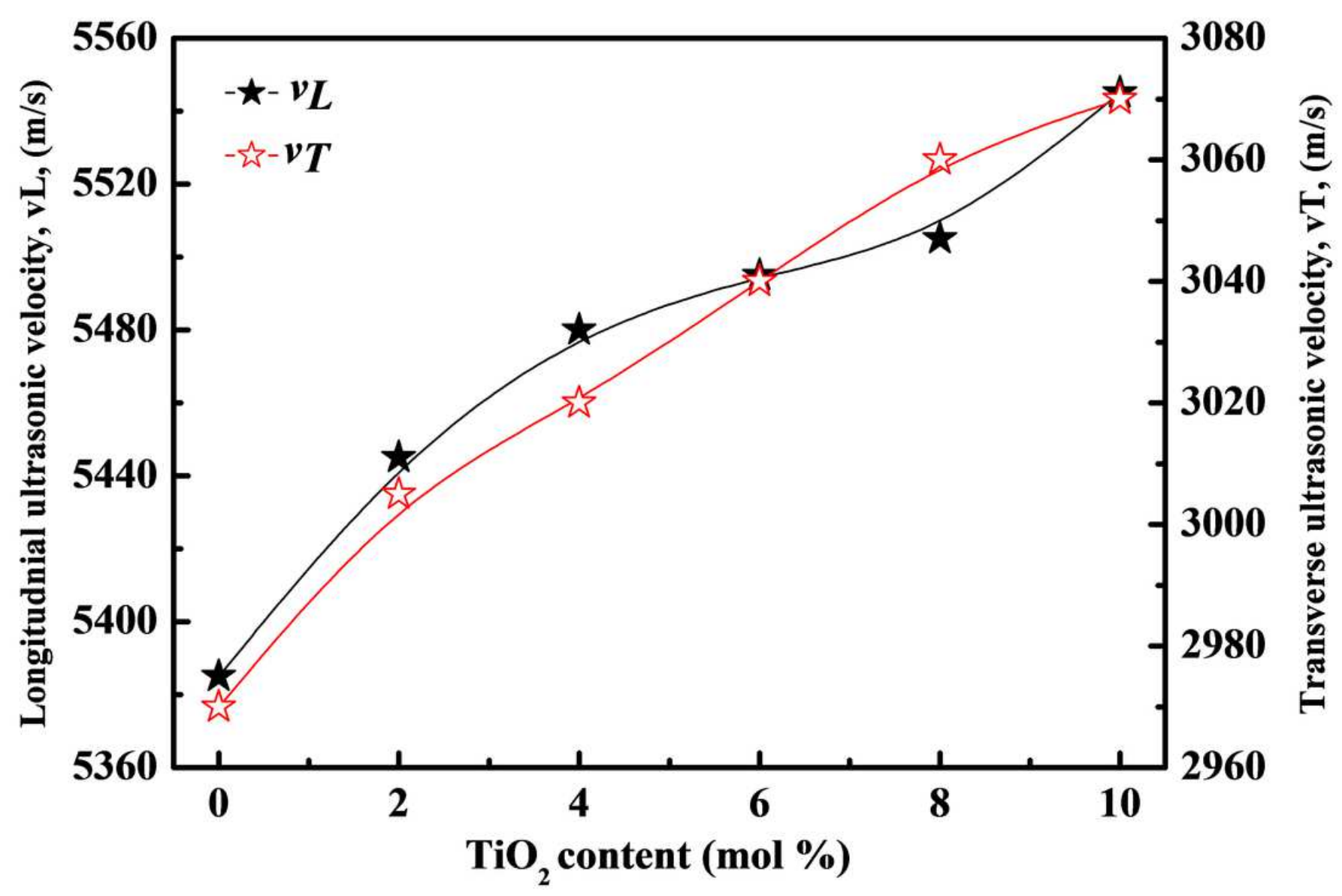

Figure 5

Ultrasonic velocities of prepared glasses with varying quantities of $\mathrm{TiO} 2$. 


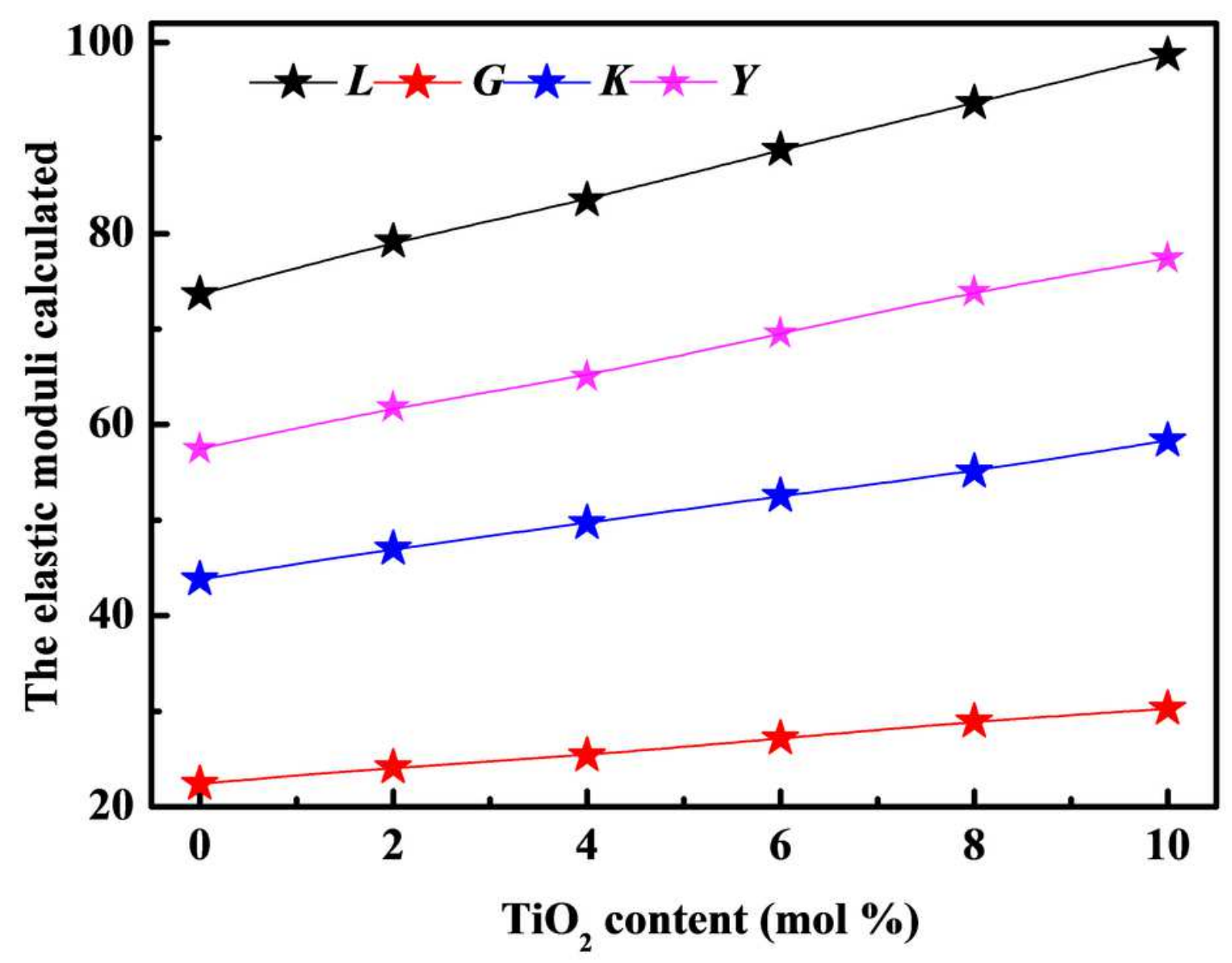

Figure 6

Experimentally elastic modules of prepared glasses with varying quantities of TiO2. 


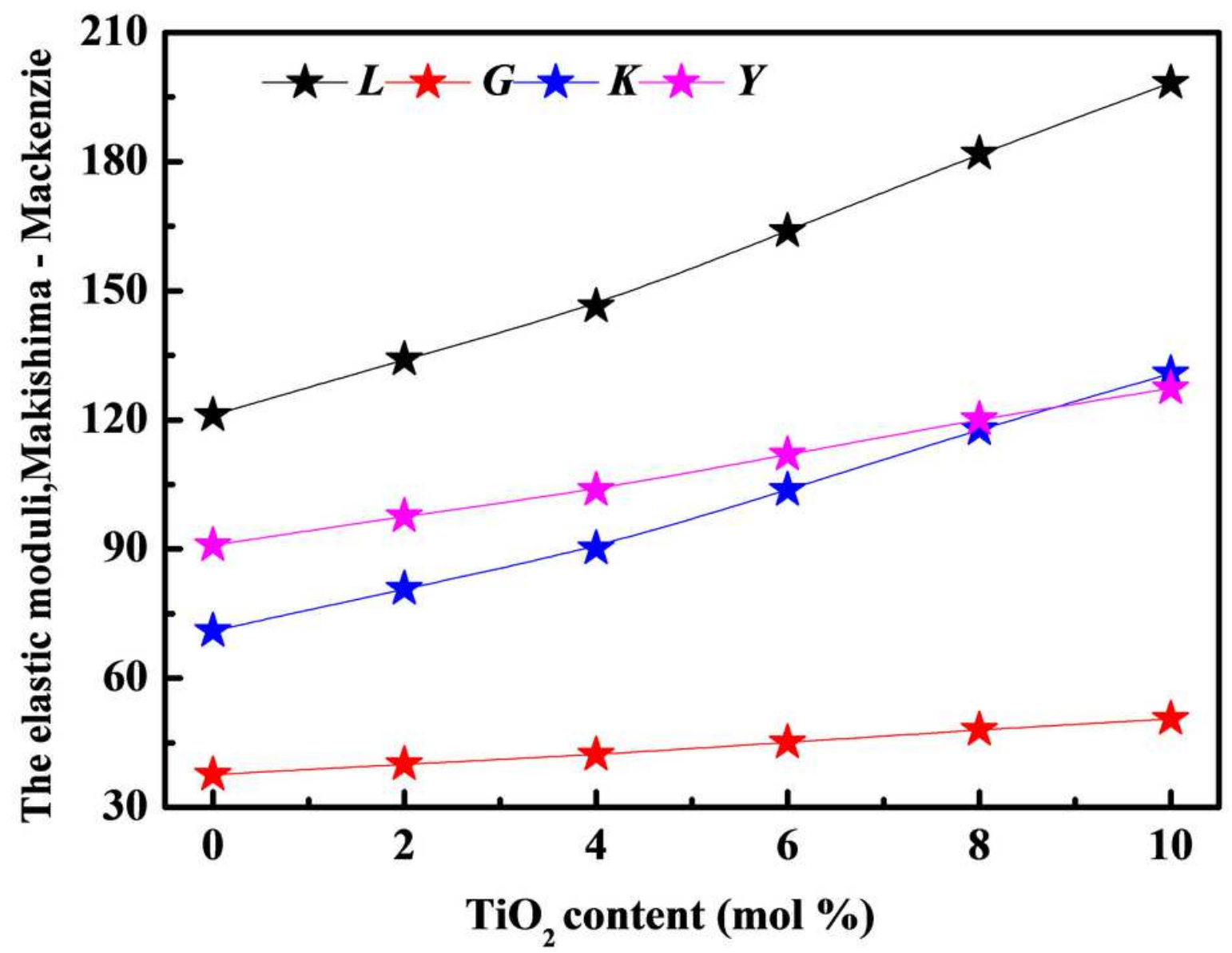

Figure 7

Theoretically elastic modules of prepared glasses with varying quantities of $\mathrm{TiO} 2$. 


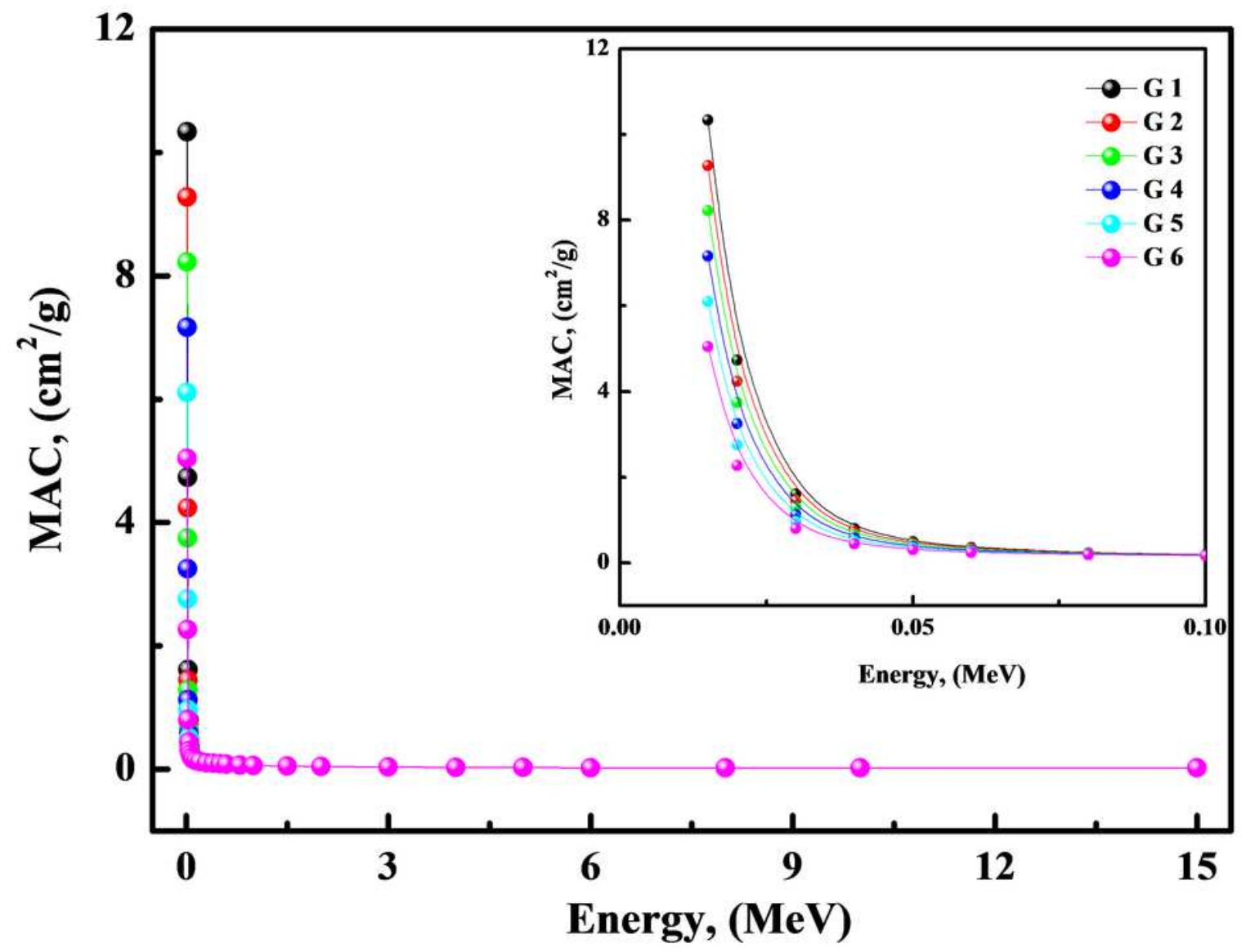

Figure 8

Mass attenuation coefficient prepared glasses a function of photon energy according to Phy-X/PSD. 


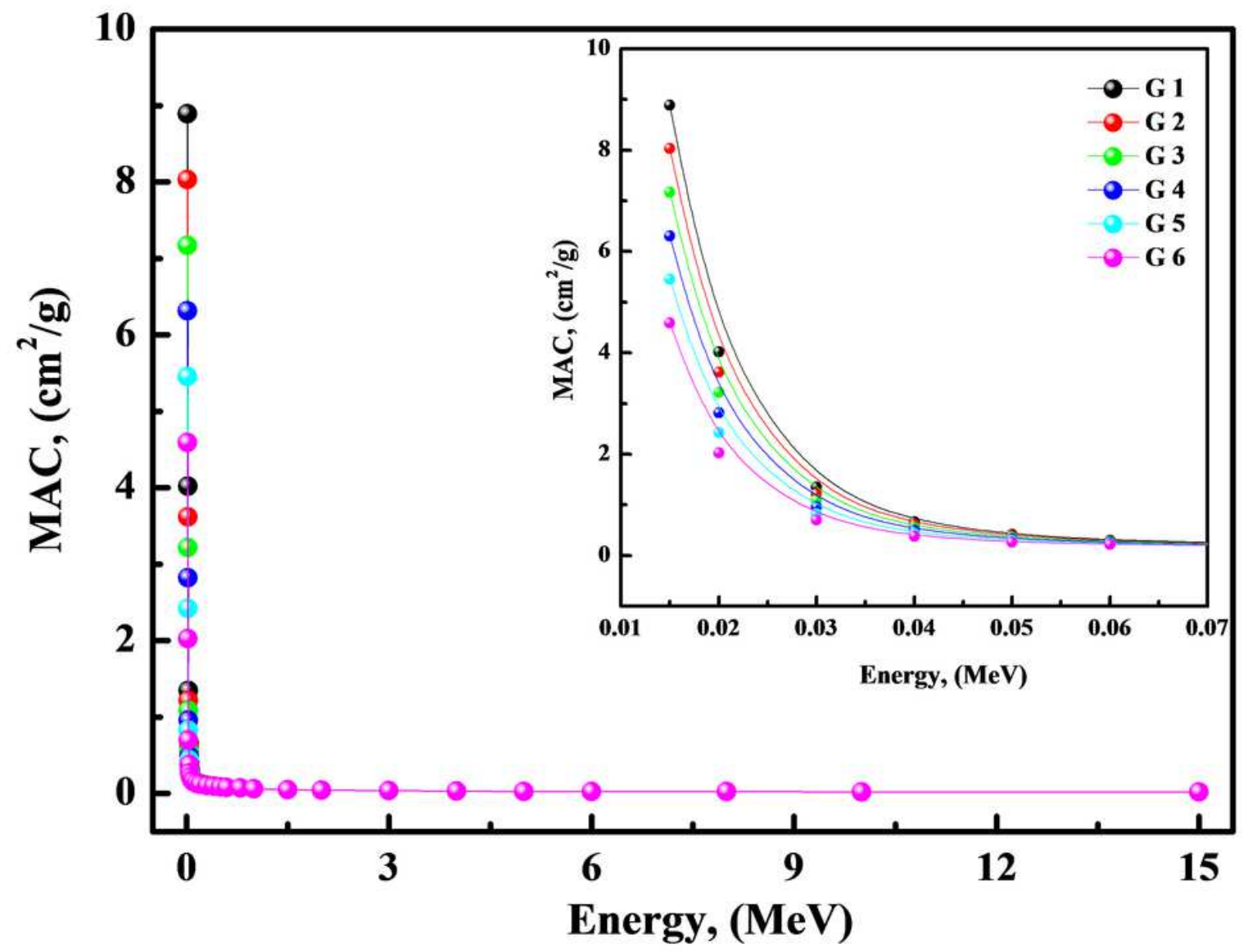

Figure 9

Mass attenuation coefficient prepared glasses a function of photon energy according to X-COM. 


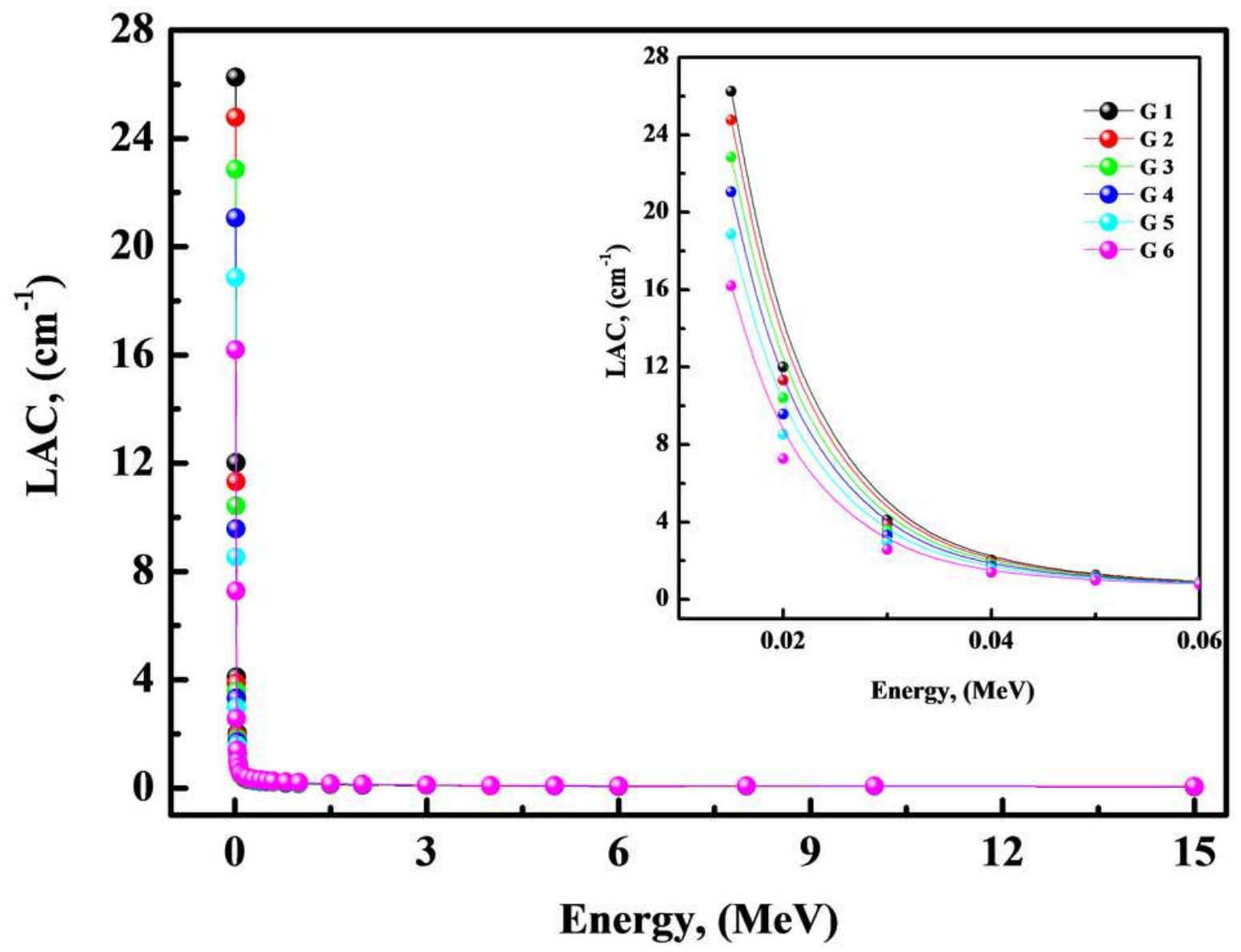

Figure 10

Linear attenuation coefficient prepared glasses a function of photon energy according to Phy-X/PSD. 


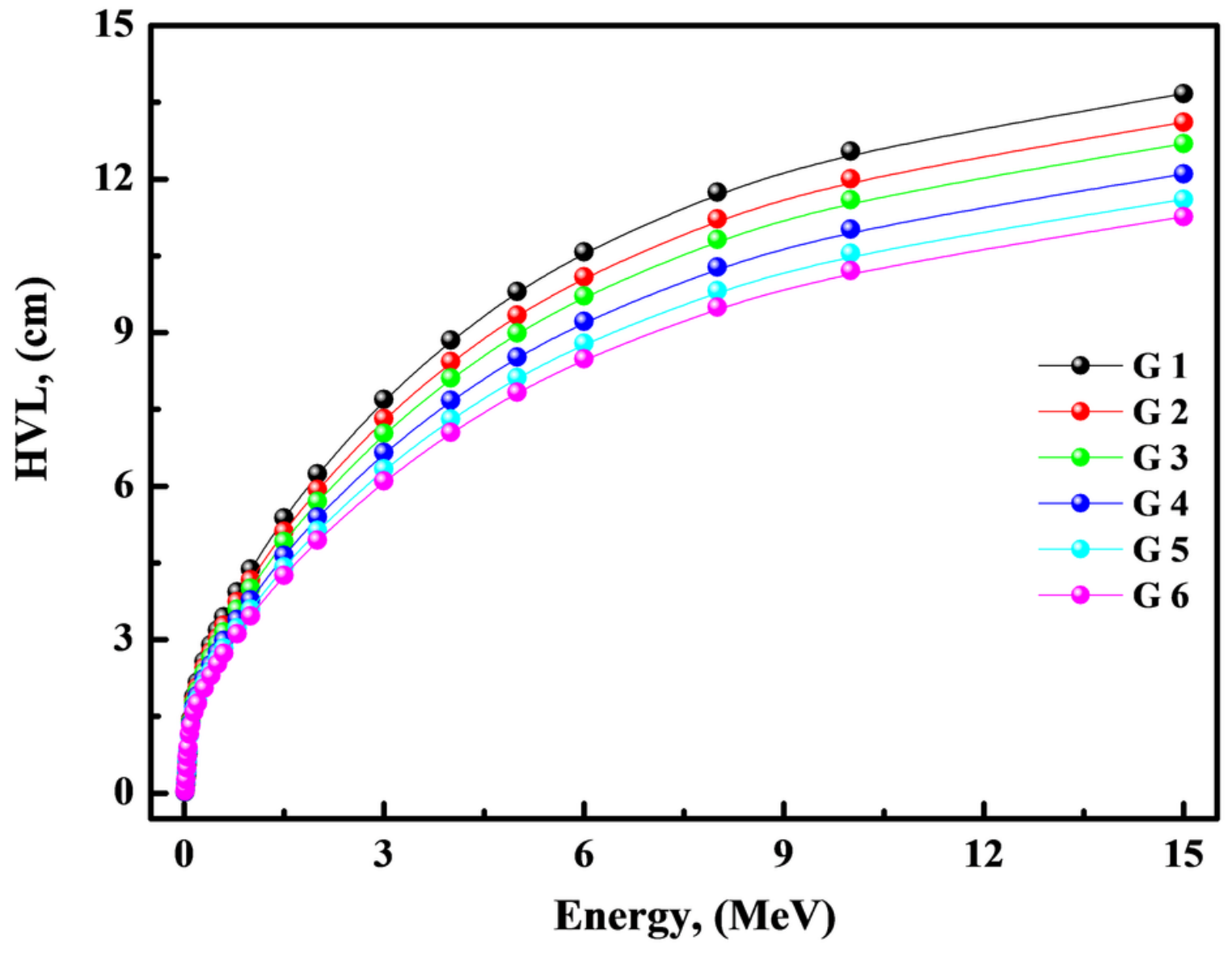

Figure 11

Have value layer prepared glasses a function of photon energy according to Phy-X/PSD. 


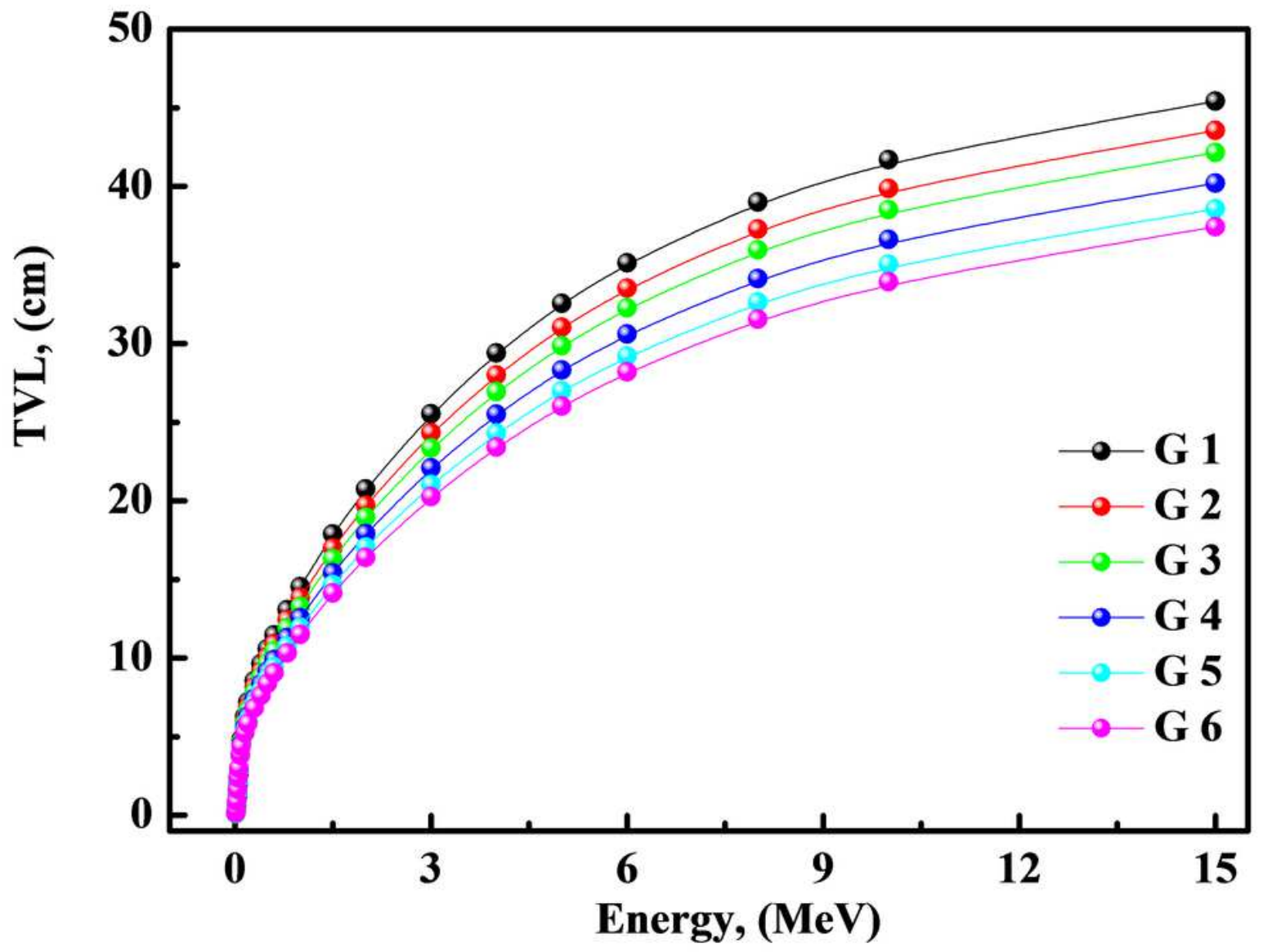

Figure 12

Tenth value layer of prepared glasses a function of photon energy according to Phy-X/PSD. 


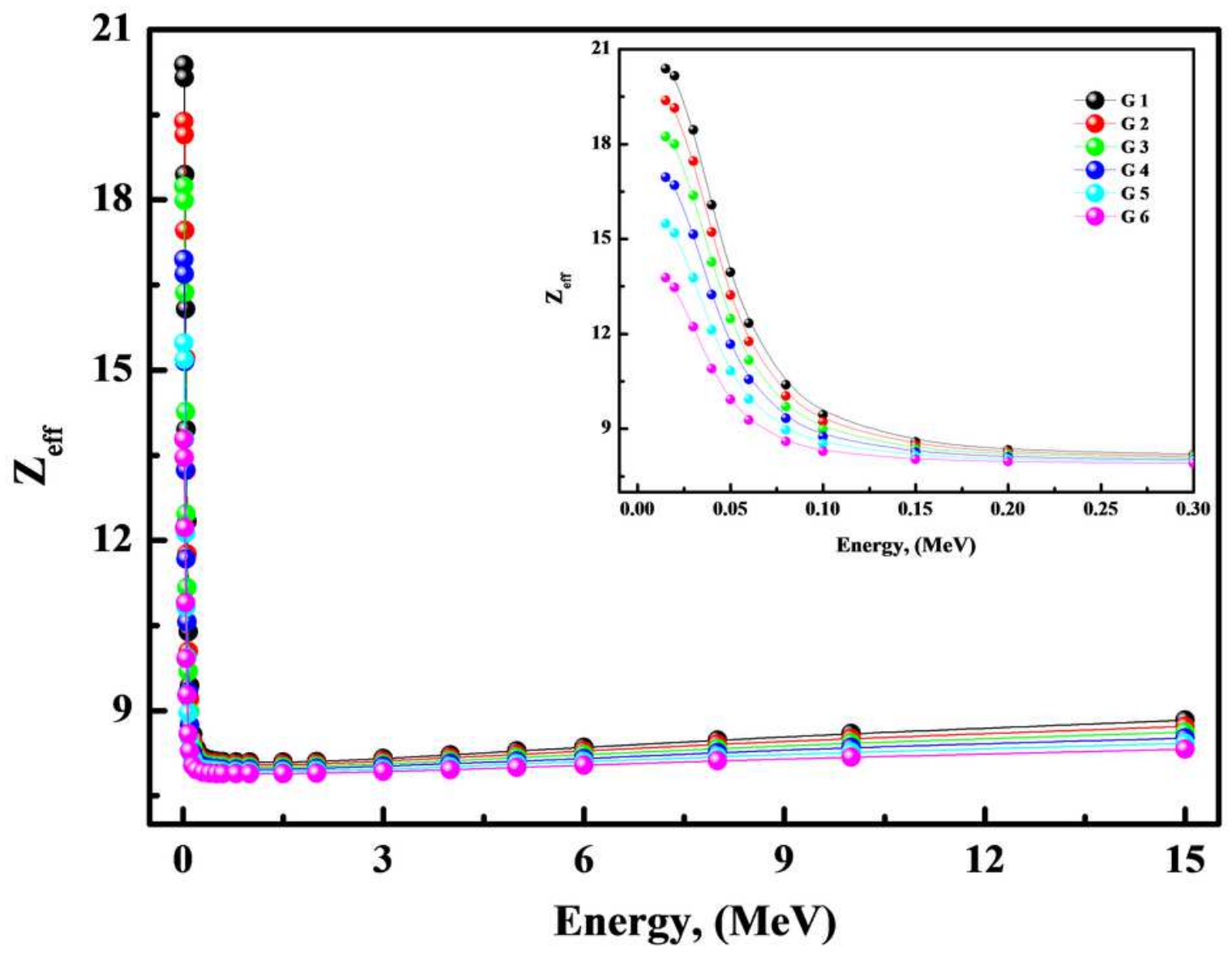

Figure 13

Effective atomic number of prepared glasses a function of photon energy according to Phy-X/PSD. 